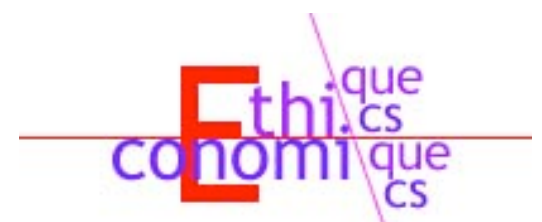

\title{
Two approaches to stakeholder identification
}

\author{
By/Par $\quad$ Alexander W. Cappelen \\ Department of Economics \\ University of Oslo \\ a.w.cappelen@,econ.uio.no
}

\begin{abstract}
$\underline{\text { ABSTRACT }}$
The paper presents two fundamentally different ways to approach the identification of stakeholders. The first is the relationship approach. According to this approach, special obligations arise between individuals or groups only if a specific relationship exists between them. The rival approach is the assignment approach. This approach challenges the claim that obligations only arise if a particular relationship exists between the company and a group. It holds that the distribution of responsibilities should be viewed as a set of pragmatic rules derived from general moral considerations. The paper discusses the extent to which these two approaches can justify the main features of the traditional stakeholder model.
\end{abstract}


Two approaches to stakeholder identification

\section{INTRODUCTION}

One of the most fundamental ethical questions is the question of whom we have obligations towards. The normative stakeholder theory provides a partial answer to this question. In contrast to the shareholder theory, as it is presented by for example Friedman (1970), it holds that companies have an obligation to take into account the interest of other agents than the shareholders. According to the stakeholder theory, the ultimate purpose of a company is to serve the interest of those who are identified as "stakeholders" (Evan and Freeman, 1993). The stakeholder theory typically identifies a list of stakeholders, shareholders, employees, customers, creditors, suppliers and the local community. These are all groups of individuals who interact with the company and who are vulnerable to the decisions made by the company. Some have argued that stakeholders are "those groups or individuals with whom the organization interacts or has interdependencies" and "any individual or group who can affect or is affected by the actions, decisions, policies, practices or goals of the organization" (Carroll, 1993, p. 60).

Interdependence can, however, only be a partial answer to the question of who a company has obligations towards. Interdependence or vulnerability is not a sufficient condition to justify the traditional list of stakeholders. Several groups that are vulnerable to the decisions made by a company, such as its competitors or potential employees, are typically not considered to be stakeholders. Furthermore, the standard stakeholder theory does not explain why interaction or vulnerability should be a source of obligations. In order to identify stakeholders, and to evaluate the traditional list of stakeholders, we need to have a theory that explains when a group has a claim on a company. Using the definition suggested by Donaldson and Preston (1995), it is necessary to develop a normative stakeholder theory that deals with the reasons why companies ought to consider stakeholder interests even in the absence of any apparent benefit.

In this paper I shall argue that there are two fundamentally different ways to approach the identification of stakeholders and to justify stakeholder rights and the corresponding obligations on the part of the company. The first is what I shall name the relationship approach. According to this approach, special obligations arise between individuals or groups if there is a specific relationship between them. This would appear to be a promising approach to stakeholder identification within the stakeholder model, and the first part of this essay analyzes whether different variants of the relationship approach can provide a plausible justification for the list of groups commonly identified as stakeholders. I then examine a rival approach which I name the assignment approach. This approach challenges the claim that obligations only arise if a particular relationship exists between the company and a group. It holds that the distribution of responsibilities should be viewed as a set of pragmatic rules derived from general moral considerations. This second section of the essay discusses how the assignment approach can be used to justify the main feature of the stakeholder model. The final section concludes. 


\section{THE RELATIONSHIP APPROACH}

The relationship approach views a company's responsibility, and the corresponding rights of stakeholder groups, as deriving from special duties that we have toward persons or groups to whom we have particular relationships. ${ }^{1}$ To defend the view that a company has special obligations towards a particular group of stakeholders one has to argue that the relationship between the company and the stakeholder group gives rise to special obligations.

Below I present three traditions that fall within the relationship approach: the voluntarist tradition, the mutual benefit tradition, and the communitarian tradition. The common feature of these traditions is that they hold that we have, or could have, different and more extensive obligations toward particular individuals if we stand in a special relationship to these individuals. However, they disagree as to what type of relationship is morally relevant.

\subsection{The Voluntarist Tradition}

According to the voluntarist tradition, mere participation in a relationship, or interdependence, is not sufficient to give rise to special responsibilities. Special obligations only arise from voluntary and informed agreements or contractual relationships. The bestknown voluntarist tradition is libertarianism (see for example Nozick (1974)). According to this theory all individuals have certain basic liberties or rights, such as the right to life and health, to property, and to liberty. These rights constitute the bounds of individual freedom of action that people cannot transgress. Individuals have these rights irrespective of the existence of any particular relationship or institutional structure. In the absence of any voluntary agreement, the only obligation we have towards other individuals is the negative duty not to violate their basic rights. Positive obligations between individuals might be legitimate, however, if they are voluntarily agreed to and the agreement did not violate any individual rights. Clearly, what constitutes a voluntary agreement is a pivotal question within the voluntarist tradition. In particular it is important whether only formal contracts should be viewed as the appropriate type of agreement or if less explicit types of consent might be viewed as voluntary agreement.

The shareholder theory, as it is presented by Friedman (1970), is a good example of a voluntarist theory. According to Friedman, managers have an obligation to maximize shareholder value because the managers have voluntarily agreed to promote the interest of the owners. A similar contract does not exist between the managers and the other stakeholders. If only formal contracts should be viewed as the appropriate type of voluntary

\footnotetext{
${ }^{1} \mathrm{I}$ use the term special duties in a broad sense, so as to include obligations that derive from voluntary agreements or contracts.
} 
agreement this explains the asymmetry between the shareholders and other stakeholders. The only obligations a company has towards its employees or its costumers are those specified by contracts and by the law in the country of operation.

However, the voluntarist tradition conforms somewhat better with the stakeholder theory if one argues that less explicit types of consent should be considered a basis for special obligations. It could be argued that when a company voluntarily enters into a relationship with some stakeholders they also tacitly accept certain obligations in addition to those specified by formal contracts. This could for example explain why firms have certain obligations towards their employees and their costumers over and above those that are specified by the law or by formal contracts. The fact that some types of interdependence are not a result of voluntary agreements, would also explain why some groups that a company interacts with, such as its competitors, should not be considered stakeholders.

However, as a basis for the stakeholder theory and as a justification for the traditional list of stakeholders, the voluntarist view has its obvious limitations. The relationship between the company and some of the traditional stakeholders, such as the local community, cannot be seen as a result of a voluntary agreement because the stakeholders often do not have any way to avoid the interaction. Furthermore, many would object to the premise in the voluntarist tradition that obligations towards stakeholders would have to be accepted voluntarily by the company.

\subsection{The Mutual Benefit Tradition}

David Hume, and more recently John Rawls and David Gauthier, have characterized the existence and necessity of social cooperation as part of the "circumstances of justice" (Hume (1986) pp. 145-153; Rawls (1971) pp. 126-130; and Gauthier (1985) pp. 10-14). According to this tradition a society should be understood as "a co-operative venture for mutual advantages" marked with both identity of interests and conflict (Rawls (1971), p. 126). Social cooperation makes possible a better life for everyone through the increase in production that results from joining forces. But there is also conflict of interests, as everyone prefers a larger to a lesser share of the benefits produced by their cooperation. This tradition is a relationship approach in the sense that obligations arise from a particular relationship: cooperation in order to create a social surplus. These obligations exist even if the relationship is not voluntary and the existence of obligations does not presuppose any voluntary agreement between the participants. According to the mutual benefit tradition, distribution should therefore take place among those who participate in social cooperation. A crucial question within this tradition is how the concept of social cooperation is construed. The answer to this question affects both who are seen as participants in social cooperation and what is considered the social surplus to be divided among the participants.

If social cooperation is interpreted narrowly as economic cooperation, then the mutual benefit tradition holds that economic transactions give rise to special obligations among the 
participants. This interpretation seems to correspond well with the traditional list of stakeholders. Owners, employees, costumers and suppliers engage in economic cooperation. It also provides a possible explanation for why certain groups, such as competitors, are not included despite the fact that they interact with the firm. However, it does not give a convincing justification of including the local community among the stakeholders, because there need not be any economic transactions between the firm and the local community. Furthermore, it does not explain why only groups that cooperate directly with the firm should be included among the stakeholders. Why should the firms' suppliers, but not the suppliers of the suppliers be included in the list of stakeholders? Given the interdependence of the world economy, the list of stakeholders would obviously become very long even if we interpret social cooperation as economic cooperation.

The main challenge to the mutual benefit tradition as a basis for stakeholder identification is how to interpret the notion of social cooperation. For some writers, such as Rawls, the society as a whole, not just its economy, should be conceived as a cooperative scheme from which everyone receives a wide range of economic and non-economic benefits. Given this interpretation of social cooperation, the mutual benefit tradition would also identify participation in the same political jurisdiction as a source of stakeholder obligations.

\subsection{The Communitarian Tradition}

According to the communitarian tradition an individual is partly defined by his relationships and the various rights and obligations that go along with them, so these commitments themselves form a basic element of personality (Miller (1988), p. 648). Rights and obligations are therefore, at least partly, defined between members of particular societies or communities at particular times. ${ }^{2}$ The morally relevant type of connection is therefore social and/or cultural. To the extent that a person has other and more extensive obligations toward individuals within the same community, communitarians would argue that delimitation of fiscal jurisdictions should correspond to such communities. Again, two important and difficult questions within this tradition are how the concept of community is construed and what type of attachments and loyalties constitute a community.

Several of the traditional stakeholders, such as the employees and the local community are typically parts of the same social and cultural community. It is often assumed that an individual would generally be a member of the community where she resides. If this assumption is correct, the communitarian tradition could be seen as justifying a company's obligations towards the local community in which it operates and its employees.

\footnotetext{
${ }^{2}$ Most communitarians would accept that there exist moral constraints on our behavior with respect to persons outside our group, but maintain that these are of a different or less extensive kind than are those toward members of our community.
} 
The main problem with using the communitarian tradition as a basis for the stakeholder model is that several of the traditional stakeholder groups, such as customers or suppliers, do not need to be part of the same community where the company has its operations. Another problem is the fact that people identify with communities on different terms, resulting in a fundamental ambiguity as to how to construe the group within which resources should be redistributed. Given the importance most people attach to national and ethnic communities, the communitarian tradition is difficult to reconcile with the fact that the national community, or a society, is not included in the list of stakeholders.

None of the three versions of the relationship approach outlined above seems to provide a convincing way to justify the traditional list of stakeholders. The voluntarist approach, particularly in its strict interpretation, would primarily justify the obligations towards owners and those stakeholders that have a contractual relationship with the firm, but cannot justify any obligations towards the local community or the suppliers. It thus seem to include too few of the traditional stakeholders. The mutual benefit tradition would justify a longer list of stakeholders, including all agents that cooperate with the firms. However, it would not include the local community. Furthermore, it would include groups not traditionally considered to be among the stakeholders. In an interdependent economy almost all companies can be said to be cooperating. Finally, the communitarian tradition would explain why groups such as employees and the local community should be included, but cannot explain why a company should have obligations towards groups, such as suppliers, unless they are members of the same communities.

The fact that the three traditions do not justify the traditional list of stakeholders should not necessarily be seen as an objection to such theories. It could instead be seen as a criticism of the traditional list of stakeholders. It is, however, problematic that the three traditions suffer from an inherent ambiguity related to the interpretation of core concepts such as the concept of voluntary agreement, social cooperation and community.

\section{THE ASSIGNMENT APPROACH}

According to the assignment approach we have the same obligations towards every human independently of the relationship we have to them. Special duties should therefore be regarded as being only "distributed general duties" and derive the whole of their moral force from general duties (Goodin (1988), p. 678). The need for a moral division of labor is in other words what explains special obligations. Writers within this tradition would reject the idea that it is the presence of a morally relevant relationship that gives a company certain obligations towards its stakeholders. They would argue that responsibilities should be distributed so as to maximize some general moral objective, e.g. to maximize welfare or utility.

There is a tension between cosmopolitan moral theories such as utilitarianism and particularist theories such as the stakeholder theory. The assignment approach, or the 
assigned responsibility model as Robert Goodin calls it, can potentially reduce such tension (Goodin (1988)). Robert Goodin argues that "a great many general duties point to tasks that, for one reason or another, are pursued more effectively if they are subdivided and particular people are assigned special responsibility for particular portions of the task." (Goodin (1995) ,p. 282). Often this has to do with the advantage of specialization and division of labor (Shue 1988). At other times, it has to do with informational requirements of doing a good job in helping others. The fact that we are limited altruists, i.e. that we care about a limited number of people, constitutes another argument for delimitation of obligations.

Identification of stakeholders might thus be understood as a pragmatic way to assign responsibility for discharging certain general duties vis-a-vis individuals to particular companies. This way of assigning duties is obviously not randomly chosen, and neither should the identification of stakeholders be. We would want to avoid waste and inefficiency in the implementation of our general duties. A particular delimitation of stakeholders is only justified to the extent that it assigns responsibility in the most efficient way. This implies that obligations should be assigned to the agent who is in the best position to fulfill the obligations. The obligations a company has would therefore depend both on characteristics of the company and on the ability of other agents, such as the government, to discharge the general duty. The assigned responsibility model can explain why it is groups that interact with a company, and that are vulnerable to its decisions, that are included among its stakeholders. It makes obvious sense to assign some responsibility for its employees and costumers to the company since the company is in a better position to take account of their interests than most other agents.

Even if the assigned responsibility model to some extent reconciles the cosmopolitan nature of general obligations with the stakeholder model, it can also be used to criticize the traditional list of stakeholders. A characteristic feature of the stakeholder model is that considerations of income distribution do not have any role in the distribution of stakeholder rights. The assignment approach would challenge this feature of the stakeholder model based on what we could call the distributional objection. In its general version this objection points out that benefits arising from special relationships might work to the disadvantage of those who are most in need (Scheffler (1997)). This effect is easily seen in the context of corporate responsibility. The rich members of the world's population are more closely connected with one another, through economic cooperation, co-residence and citizenship, than with the poor. If the stakeholder rights are delimited to groups constituted by such relationships, the result will be that rich people take responsibility for rich people and poor people take responsibility for poor people and this is not necessarily an efficient way to divide moral labor.

\section{CONCLUSION}

Interdependence cannot be a sufficient condition for the existence of stakeholder obligations. Is there any other type of relationship that can explain the traditional list of stakeholders? In this paper I have discussed three possible types of relationships; contractual, economic and 
social. Important traditions in moral philosophy identify these relationships as the basis for special obligations. However, these traditions do not succeed in justifying the traditional list of stakeholders. One response to this could be to revise the list of stakeholders. Another response could be to abandon the relationship approach and the search for a unique relationship as a basis for stakeholder obligations. In many ways the assignment approach is a more promising way to justify stakeholder obligations than the relationship approach. According to this approach, stakeholder obligations should be seen as a pragmatic way to share moral labor between different agents. This would explain the importance attached to interdependence in the traditional list of stakeholders without claiming that it is the existence of interdependence as such that gives rise to the obligations.

The assignment approach also seems to be better suited to handle the fact that companies operate under very different economic, social and political contexts and that these conditions affect the type of obligations they have. It can for example explain why companies have special responsibilities when they operate in developing countries. If stakeholder obligations are seen as general duties that are assigned to the agents most capable of fulfilling them, it makes sense to assign more obligations to companies in countries where the government is weak or unwilling to take their part of the obligations. 


\section{REFERENCES}

CArroll, A. (1993), Business and Society: Ethics and Stakeholder Management (SouthWestern Publishing, Cincinnati)

Donaldson, T. and L. E. PRESTON (1995), 'The Stakeholder Theory of the Corporation: Concepts, Evidence, and Implications', Academy of Management Review 20(1), 65-91.

Evan, W. M. and R. E. Freeman: $(1993<9<$ ?>, 'A Stakeholder Theory of the Modern Corporation: Kantian Capitalism', in G. D. Chryssides and J. H. Kaler: 1993, An Introduction to Business Ethics, Chapman and Hall, London, pp. 254-266.

Friedman, M. (1970), 'The Social Responsibility of Business Is To Increase Its Profits', New York Times Magazine (September 13).

GaUthieR, D. (1985), Morals By Agreement, London: Clarendon Press.

Goodin, R. (1988), “What Is So Special About Our Fellow Countrymen?”, Ethics 98, no. 4.

Goodin, R. (1995), Utilitarianism as a Public Philosophy, Cambridge, Cambridge University Press.

Hume, D., (1986), Enquiries Concerning Human Understanding, New York: Oxford University Press

MiLLER, M. (1988), “The Ethical Significance of Nationality”, Ethics 98, no. 4

RAWLS J. (1971), A Theory of Justice, New York: Oxford University Press.

SCHEFfLeR, S. (1997), "Relationships and Responsibility," Philosophy \& Public Affairs 26, no. 3 .

SHUE, H. (1988), “Mediating Duties,” Ethics 98, no. 4. 